ISSN: 2581-8341

Volume 04 Issue 11 November 2021

DOI: 10.47191/ijcsrr/V4-i11-06, Impact Factor: 5.825

IJCSRR@ 2021

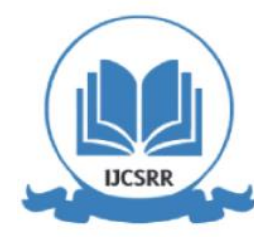

www.ijcsrr.org

\title{
Inventory Management Practices of Micro, Small and Medium Grocery Stores in Daet, Camarines Norte
}

\author{
Ryan Edison G. Secretario, MBA ${ }^{1}$, Girly H. Naval, DBA ${ }^{2}$ \\ ${ }^{1}$ 24Task LLC. \\ ${ }^{2}$ Camarines Norte State College
}

\begin{abstract}
Sourcing, storing and selling are the three very significant processes in the practice of inventory management. These processes are the focus of assessment of this research to a group of selected MSM grocery stores in Daet, Camarines Norte. Specifically, it sought answers to the following questions: 1) What is the profile of the MSM grocery stores in Daet, Camarines Norte in terms of length of the business operation, current capitalization; and total number of inventory management personnel? 2) What are the existing inventory management practices of grocery stores and their assessment of the level of effectiveness in terms of sourcing, storing, and selling? and, 3) Is there a significant relationship between the profile of the MSM grocery stores and the assessment of the level of effectiveness of the inventory management practices of grocery stores?
\end{abstract}

The study covered 150 respondents composed of MSM grocery stores. Descriptive-correlational method and F-test (One Factor Analysis of Variance) were used in the gathering and treatment of data. Frequency count and percentage were employed to determine the number of respondents characterized by each of the items in the profile. Weighted mean and adjectival ratings were utilized in marking the inventory management practices as well as the challenges encountered by MSM grocery stores. Pearson's Product-Moment Correlation and the Somers's Delta using the SPSS software was used in determining the significant relationship between the level of effectiveness of the inventory management practices of MSM grocery stores and their profile.

The findings of the study revealed that majority or 38 percent of the MSM grocery stores are already existing for 4 to 6 years with less than Php 3,000,000 current capitalization and most of them admitted that they had no particular employee assigned as inventory management personnel. The existing inventory management practices along the sourcing and storing process were all absolutely effective with ABC Classification System being the highest indicator. Moreover, findings showed that the inventory management practices for selling were 50 percent absolutely effective and 50 percent highly effective, where Enterprise Resource Planning (ERP) was the highest indicator. In the correlation analysis conducted, it was found out that the length of business operation and the level of effectiveness of inventory management practices of MSM Grocery stores along sourcing and storing are not significantly related unlike selling as an inventory management process which resulted to a significant correlation. Further, all other profiles such as current capitalization and the number of inventory management personnel have no significant relationship to the effectiveness of the inventory management practices of the respondents.

KEYWORDS: Inventory management practices, micro, small and medium grocery stores, Sourcing, Storing, Selling

\section{INTRODUCTION}

Inventory management is a systematic approach to sourcing, storing, and selling inventories, both raw materials (components) and finished goods (products). In business terms, inventory management means the right stock, at the right levels, in the right place, at the right time, and at the right cost as well as at the right price. These three variables helped businesses to maximize their profit to help their business grow (Intuit QuickBooks 2020). Thus, managing inventories is important to businesses because it helps in the proper planning of the materials needed so as to identify the gap between the desired and the actual level of materials, allocation of resources, purchasing, sales and employment of staff and everything concerned to human resources management all of which reduces on the costs incurred by the organization in the production departments for improved performance of the organization (Sabure, 2020).

As regards to one of these variables which is sourcing, Kakwezi and Nyeko (2014) stated that sourcing or procurement performance is associated with effectiveness and efficiency of procurement operations. Procurement performance takes a gander at the degree to which the procurement function accomplishes the organizational procurement objectives and targets. Therefore, the sourcing function must be assessed to establish its performance level (Neely, 2015). Moreover, since a store or a business involves services and supports the organizational and functional structure of a commercial or industrial enterprise with welldefined objectives receipt, custody, control and supply of materials and products, proper storing of products is essential to maintain the supply chain. According to Aranda and Ahmed (2016), although storing has been practiced among businesses, its 


\section{International Journal of Current Science Research and Review}

ISSN: 2581-8341

Volume 04 Issue 11 November 2021

DOI: 10.47191/ijcsrr/V4-i11-06, Impact Factor: 5.825

IJCSRR@ 2021

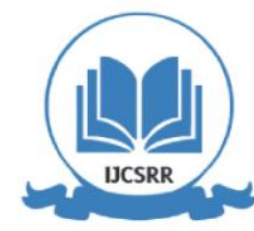

www.ijcsrr.org

concept has been changing and expanding its area of responsibility. Therefore, best-practice companies have designed storage systems to meet the needs of the current and planned mix of storage types and have optimized storage locations and layouts to fit product without the need to restack or palletize it once received (Vitasek, 2018). Aside from sourcing and storing, the inventory management also deals with selling functions or the manner of outbound inventories. Whereas, Murray (2020) stated that an efficient inventory management system accurately forecasts how much inventory will need based on sales activity. This way, it can place orders accordingly to prevent overstock and stockout. It must understand how much demand consumers have for a product as well as the product's depreciation rate.

Furthermore, important variables such as sourcing, storing and selling contributed to the overall efficiency and profitability of businesses for their operations. Shin et al., (2015) studied the relationship between inventory management efficiency and companies' profitability; the researchers determined that by examining the financial data of 1,289 firms over three fiscal years, the initial result leads them to examine the relation between profitability and inventory management efficiency. Moreover, better inventory management efficiency is positively related to firm's profitability. Furthermore, Salawati et al., (2012), analyzed the impact of inventory management on performance. They empirically examined the relationship between inventory management and firm performance in Malaysia. Their finding was that inventory management is positively correlated with firm performance.

Moreover, inventory management has progressed into an extremely studied and practiced concept in the business. One dominant method and recent development in inventory management is JIT (Just-in-Time). This mechanism was invented by the Toyota Production System (TPS), which lessens inventory and lead time and increases quality at the same time. JIT implies handling of inventory in a much-disciplined way.

However, even there were existing inventory management practices, there are external or uncontrollable factors that can affect its implementation. Njoroge et al., (2016) stated that the external environment is a set of factors that are exogenous in relation to the organization and influence organizational efficiency; The external environment of organizations is an integrated, dynamically developing characteristic, which includes a complex of social, technological, economic, political and legal factors that are beyond the control of business and impose their limitations on the activities of the organization. The survival and success of an organization depends on the skillful interaction of the company's management with the external environment (Kuznetsova and Alekseeva, 2016).

Furthermore, in this study, it was observed that in the Municipality of Daet, Camarines Norte, is turning to be a fastgrowing town and one of the prime centers of economic activity in the province of Camarines Norte. In the context of national economic development, it is considered as the number one most competitive town in the Philippines in the year 2013 as determined by the competitiveness level of the Local Government Unit of Daet. It is being spearheaded by the National Competitiveness Council (NCC) Philippines through the regional competitiveness coordinating committees. According to the Department of Trade and Industry and Local Government Unit Office of Daet, the municipality has a high number of Micro, Small and Medium (MSM) grocery stores with over 150 within the locality, as of 2020.

In the local scenario, grocery stores in Daet face similar situation of having problems concerning inventory management. It is because some of the grocery stores in Daet have no concrete mechanism with regards to inventory management. Additionally, some of these grocery stores are using practices that may not be relevant to their current inventory management. Based on the initial interview with some of the owners of grocery stores, some of them do not apply inventory management, which lead to a number of expired and unused products and spoilage of perishable items. Apart from that, there are grocery stores that can easily run out of products faster even though the said products are not in demand in the market. In fact, these problems could be avoided by applying appropriate inventory management strategies. The downfall of some grocery stores results from the fact that they are simply unaware of or do not consider the inventory management. Hence, the conduct of this study was deemed essential as it identifies the most appropriate inventory management practices for Micro, Small and Medium (MSM) grocery stores.

\section{METHODOLOGY}

This chapter presented the research design, respondents of the study, how the researcher gathered data, the research method employed in the study, the data collection techniques that were used and the target population, the sample size and sampling techniques as well as the data analysis method used by the researcher to obtain the objectives of the study.

\section{Methods of Research}

To assess the inventory management practices of Micro, Small and Medium (MSM) Grocery Stores in municipality of Daet, Camarines Norte, the researchers used the descriptive correlation design to gather information. This method was considered as most appropriate design because of its analytical functions especially in the discussion of the profile of respondents, length of the business, size of the business, current capital of the business, and total number of inventory management personnel of the 


\section{International Journal of Current Science Research and Review}

ISSN: 2581-8341

Volume 04 Issue 11 November 2021

DOI: 10.47191/ijcsrr/V4-i11-06, Impact Factor: 5.825

IJCSRR@ 2021

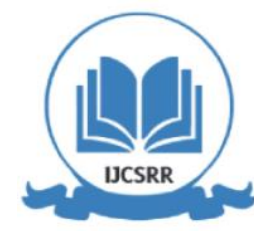

www.ijcsrr.org

Micro, Small and Medium (MSM) Grocery stores. The researchers used this method to summarize the characteristics of the data set.

\section{Description of Respondents}

The respondents are business owners/manager of Micro, Small, and Medium Enterprise grocery stores come from the municipality of Daet, Camarines Norte who are operating under merchandising and retail industry. The respondents were business proprietors that are registered in the Municipality of Daet that qualify under the classification of a grocery store. Another criterion in the selection of a qualified respondent is that the store should be in an active status or currently operational at the time of the survey.

\section{Statistical Treatment of Data}

The statistical data gathered were properly consolidated, tabulated, statistically presented, analyzed and interpreted. Frequency count and percentage were used in getting the profile of Micro, Small, and Medium Grocery stores. For the second objective which is about the effectiveness of the existing inventory management practices of MSM grocery stores, weighted mean was used. On the other hand, for the third problem which is about the significant relationship of the effectiveness of inventory management practices among MSM grocery store respondents and the business profile, Pearson's Product-Moment Correlation and Somers's Delta were used to significantly treat the data.

\section{RESULTS AND DISCUSSIONS}

This chapter contains the presentation and analysis of data gathered by the researcher with the use of survey questionnaires. Findings were made with the use of percentage, weighted mean, ranking, Pearson's Product-Moment Correlation, the Somers' Delta. The central objective of this study is to determine the inventory management practices of Micro, Small and Medium Grocery Stores in Daet, Camarines Norte. The data were set into four main parts: profile of the business; inventory management practices of grocery stores, their assessment of the level of effectiveness and the significant relationship between the business profile and their level of effectiveness on the inventory management practices.

\section{Profile of Respondents}

Tables 1 to 3 presented the profile of the MSM grocery stores as respondents of the current study. The variables used were limited to the length of the business operation, current capitalization, and total inventory management personnel. It aimed to impart a basis for the analysis of the research problem.

Length of Business Operation. The table reveals that 57 respondents or 38 percent existed for four to six years while four respondents or three percent for 20 years and above.

Table 1. Length of Business Operation

\begin{tabular}{lcc}
\hline Number of Years in Business & Frequency & Percentage $(\%)$ \\
\hline Below 1 year & 16 & 11.0 \\
$1-3$ & 30 & 20.0 \\
$4-6$ & 57 & 38.0 \\
$7-9$ & 26 & 17.0 \\
$10-12$ & 14 & 2.0 \\
$13-15$ & 3 & 2.0 \\
$16-19$ & 0 & 0.0 \\
20 and above & 4 & 2.0 \\
Total & 150 & 100.0 \\
\hline
\end{tabular}

This indicates that MSM grocery stores have sustained, surpassed, and withstand the first three years of criticalness became themselves as fully-operational enterprises beyond four years after establishment. Their experiences and exposure in the field have helped them became aware of the proper timing and strategies once stricken by external forces, this is the reason why the most of MSM grocery stores in Daet were existed between four to six years. 


\section{International Journal of Current Science Research and Review}

ISSN: 2581-8341

Volume 04 Issue 11 November 2021

DOI: 10.47191/ijcsrr/V4-i11-06, Impact Factor: 5.825

IJCSRR@ 2021

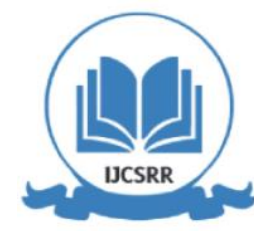

www.ijcsrr.org

This finding was supported by a study carried out by Ferreiro et al, (2018), their study concluded that from the selected sample, the survival rate reaches 90.8 percent by the fourth year, and continue to operate at 100 percent, they also found that the average age of the businesses is 6.7 years and these resulted to business sustainability to a greater extent.

However, there are only four MSM grocery stores existed for more than 20 years and above in municipality of Daet, Camarines Norte. This implies that they gained business experiences as to how they will deal with the challenges and sustain operations. Additionally, this entails that only few grocery stores had survived the critical period and overcome the challenges throughout the years both internal and external that made themselves as one of the pioneers of grocery stores in Daet, Camarines Norte. It was supported by the study of Hamzani and Achmad (2015), they found that from 200 MSME respondents, there are only 12 respondents or six percent which have existed from 20 years and above, it also showed that this result was the lowest among all the group of ages given in their study. These findings were also similar to the current study with lowest percentage of respondents existed for 20 years and above range.

Current Capitalization. The table reveals that 68 respondents or 45 percent had a capital of below 3,000,000 followed by 62 or 41 percent with a capital of $3,000,000$ to $14,999,999$. The lowest result was with the capital of $15,000,000$ to $26,999,999$ with twenty or 14 percent.

Table 2. Profile of the Respondents in terms of Current Capitalization

\begin{tabular}{lcc}
\hline $\begin{array}{c}\text { Current Capitalization } \\
(\text { Php })\end{array}$ & Frequency & $\begin{array}{c}\text { Percentage } \\
(\%)\end{array}$ \\
\hline Below 3,000,000 & 68 & 45.0 \\
$3,000,000-14,999,999$ & 62 & 41.0 \\
$15,000,000-26,999,999$ & 20 & 14.0 \\
Total & 150 & 100.0 \\
\hline
\end{tabular}

This implies that 45 percent of the MSM grocery stores had an estimated capital of less than three million pesos. This figure can be inferred that the businesses in Daet, Camarines Norte was predominantly micro in capital size; however, it is not impossible to remain in business even with limited capital. The data show that with minimal capitalization of fewer than Php $3,000,000$, the MSM grocery stores were able to survive in the industry. This infers that the MSM grocery stores' limited capital was enough to sustain their business operations, thus, to survive in business.

This articulates that staying in business as MSM grocery stores is not impossible even with limited capitalization because they can easily sustain their current resources throughout the years despite of low growth. The findings show that with minimal estimated capitalization of Php 3 million and below, the MSM grocery stores were able to survive business challenges and competitions for over a decade. They maintain their status at a minimum requirement for startup capital, but stays in business despite minimal assets. This implies MSM grocery stores' limited current capitalization worth were enough to sustain operations; hence they are able to survive business.

Total Number of Inventory Management Personnel. Table shows that 41 percent of MSM grocery stores do not employ inventory management personnel, while 31 percent of these businesses hired one (1) employee, 22 percent for two employees, 5 percent for three employees and 1 percent for five employees.

Table 3. Number of Employees Involved in Inventory Management

\begin{tabular}{ccc}
\hline $\begin{array}{c}\text { Inventory Management } \\
\text { Personnel }\end{array}$ & Frequency & Percentage (\%) \\
\hline 0 employee & 62 & 41.0 \\
1 employee & 46 & 31.0 \\
2 employees & 33 & 22.0 \\
3 employees & 8 & 5.0 \\
5 employees & 1 & 1.0 \\
Total & 150 & 100.0 \\
\hline
\end{tabular}

According to survey results, no employee assigned in inventory management for every grocery store has occupied a greater percentage and most of them belong to micro enterprise. This implies that most of the grocery stores in Daet, Camarines Norte did not assign personnel for their inventory management because they designate their employee to handle multiple tasks and to not hire an additional employee. This shows that total inventory management personnel and capitalization of businesses were 


\section{International Journal of Current Science Research and Review}

ISSN: 2581-8341

Volume 04 Issue 11 November 2021

DOI: 10.47191/ijcsrr/V4-i11-06, Impact Factor: 5.825

IJCSRR@ 2021

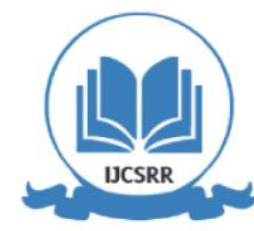

www.ijcsrr.org

interrelated. The workforce that the enterprise employed supports the capital they have, the more capital they have, the more manpower they need to employ in their business the paltry difference was founded on the nature or industries where the enterprise comprises.

Additionally, most of the businesses that have one to five inventory management personnel were existed from the Small and Medium category. This exemplified the concept of capitalization and inventory management control as interconnected. The enterprises that have higher capital have the ability to hire more employees and this significantly contributed to the inventory management control. This concept was further supported by Chitale and Gupta (2014) stated that managing inventory through employment of staff and everything concerned to human resources management reduces the costs incurred by the organization in the production departments and improved performance of the organization.

Furthermore, it also implies that the MSM grocery stores maintain minimal number of hired personnel, and this would mean least expenses for employees' benefits and salaries. This is contributory factor to the longevity of the MSM grocery stores existence in the business field for they are able to serve numerous customers without hiring many employees. This marginal number of employees involved in their operations is just enough to sustain their need for continuous operations.

Other implication, most of the businesses have one to five inventory management personnel. This exemplifies the concept of capitalization and inventory management control as interconnected. The enterprises that have higher capital have the ability to hire more employees and this significantly contributed to the inventory management control. Chitale and Gupta (2014) stated that managing inventory through employment of staff and everything concerned to human resources management reduces the costs incurred by the organization in the production departments and improved performance of the organization.

\section{Existing Inventory Management Practices of Grocery Stores and Assessment to its Level of Effectiveness}

Table 4 presents the data on the MSM grocery stores inventory management practices along three (3) areas such as sourcing, storing and selling. The inventory management practices of the respondents aim to impart a basis for the analysis of the research main objectives which is to determine whether there is a significant difference between the inventory management practices among micro, small and medium grocery stores.

Sourcing. Table 4 shows the respondents see their sourcing using the 5-point scale presented in the research questionnaire. The figures reveal that among the sourcing indicators, EOQ Model had the highest weighted mean score of 4.67 interpreted as absolutely effective. Overall, the general weighted mean of 4.37 means that the sourcing as an inventory management practice is absolutely effective by all MSM grocery stores. The data presented imply that the MSM grocery stores are efficient in implementing a sourcing that enables them to survive numerous challenges.

Table 4. Inventory Management Practices of Grocery Stores and Assessment to its Level of Effectiveness in terms of Sourcing

\begin{tabular}{|c|c|c|c|c|c|c|c|}
\hline & \multirow{3}{*}{ Indicators } & \multicolumn{4}{|c|}{ Inventory Management } & \multicolumn{2}{|c|}{ Level of Effectiveness } \\
\hline & & \multicolumn{4}{|c|}{ Practices } & \multirow[b]{2}{*}{ WM } & \multirow[b]{2}{*}{$\begin{array}{c}\text { Interpretati } \\
\text { on }\end{array}$} \\
\hline & & $\begin{array}{l}\text { Yes } \\
\text { (f) }\end{array}$ & $(\%)$ & $\begin{array}{l}\text { No } \\
\text { (f) }\end{array}$ & $(\%)$ & & \\
\hline 1. & $\begin{array}{l}\text { EOQ MODEL- Calculates the order or incremental } \\
\text { costs to process set up and order of the units }\end{array}$ & 129 & 86 & 21 & 14 & 4.67 & $\mathrm{AE}$ \\
\hline 2. & $\begin{array}{l}\text { JUST IN TIME (JIT) - Goods are ordered only when } \\
\text { the consumer makes a purchase }\end{array}$ & 99 & 66 & 51 & 34 & 4.39 & $\mathrm{AE}$ \\
\hline 3. & $\begin{array}{l}\text { REORDER POINT- A practice that triggers an action to } \\
\text { replenish that particular inventory stock }\end{array}$ & 69 & 46 & 81 & 54 & 4.32 & $\mathrm{AE}$ \\
\hline 4. & $\begin{array}{l}\text { CROSS-DOCKING- A practice which unload } \\
\text { inbound items in a truck, holding it in a warehouse for a } \\
\text { short period of time, and loading it onto another truck } \\
\text { for outbound shipping }\end{array}$ & 57 & 38 & 93 & 62 & 4.28 & $\mathrm{AE}$ \\
\hline 5. & $\begin{array}{l}\text { DROPSHIPPING- A practice where seller accepts } \\
\text { customer orders but does not keep goods sold in stock } \\
\text { Average Weighted Mean }\end{array}$ & 75 & 50 & 75 & 50 & $\begin{array}{l}4.20 \\
4.37\end{array}$ & $\begin{array}{l}\mathrm{HE} \\
\mathrm{AE}\end{array}$ \\
\hline
\end{tabular}

Scale:

$$
\begin{aligned}
& \text { 4.21-5.00 - Absolutely Effective (AE) } \\
& \text { 3.41-4.20 - Highly Effective (HE) } \\
& \text { 2.61-3.40 - Moderately Effective (ME) } \\
& \text { 1.81-2.60 - Slightly Effective (SE) } \\
& \text { 1.01-1.80 - Not Effective (NE) }
\end{aligned}
$$

With these results, it revealed that all of the inventory management practices in terms of sourcing such as EOQ model, Just in time (JIT), Reorder point, cross-docking and drop shipping are absolutely effective according to the grocery stores owners. 


\section{International Journal of Current Science Research and Review}

ISSN: 2581-8341

Volume 04 Issue 11 November 2021

DOI: 10.47191/ijcsrr/V4-i11-06, Impact Factor: 5.825

IJCSRR@ 2021

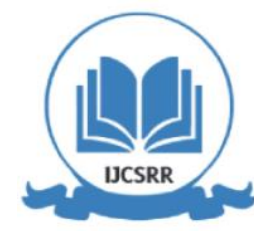

www.ijcsrr.org

These can contribute to the business operations of the enterprise particularly in relations to procurement or inbounding of their inventories.

The EOQ Model indicator has the highest percentage to the total respondents. This implies that most of the MSM grocery stores are implementing the said model, whereas, EOQ ensures the right amount of inventory ordered per batch. It was sustained by the study of Arunkumar and Nishad (2018), they found out that the EOQ technique of inventory management results in reduction in holding and ordering cost.

One reason why the EOQ model is the most practiced and effective inventory management for MSM grocery stores in sourcing variable because most of them seeks to ensure that the right amount of inventory and their products were ordered per batch and this means that a grocery stores does not have to make orders too frequently and there is not an excess of inventory sitting on hand. It was supported by the study of Victor (2018), revealed that in implementation of vendor management, EOQ model will lead to enhanced operational performance in terms of reduced inventory holding costs, optimal stock out and stockturn rates and improved return on investment. In connection to this, crossdocking was revealed the less practiced inventory management among the five models in terms of sourcing.

One explanation that could support the findings is that MSM grocery stores are predominantly micro in business size; this means that they do no longer need for large number of goods to be delivered to them since cross docking deals with bulky shipments. Another explanation, majority of the MSM grocery stores are relying on their local suppliers than the far distant suppliers and it required several logistics processes of transshipping inventory in a flow-center by unloading the shipments from the inbound trucks directly to the outbound trucks. But since majority of the businesses in Daet, Camarines Norte is micro enterprises, the need for huge shipments are often unnecessary because of their limited capital.

Furthermore, dropshipping is the lowest indicator when it comes to effectiveness of inventory management practices. This implies that MSM grocery stores rated this model as less effective compared to the other indicators. The primary reason could be because all of the grocery stores in municipality of Daet have their own physical store and need to display different grocery products rather than sell products to their buyers without actually stocking the items in their store, this model is used to purchase the item from a third party and has it shipped directly to the customer.

Storing. Table 5 shows the respondents see their storing using the 5-point rating scale presented in the research questionnaire. The figures reveal that among the storing indicators, ABC Classification had the highest rank percentage of 85 percent and weighted mean score of 4.57. On the other hand, the lowest rank when it comes to the most practiced and effective inventory management among all the indicators is the perpetual inventory management with 4.07 weighted mean. All indicators in storing variable were presented on the table 5 obtained a general weighted mean of 4.29 means that the storing as an inventory management practice is absolutely effective by all MSM grocery stores.

Table 5. Inventory Management Practices of Grocery Stores and Assessment to its Level of Effectiveness in terms of Storing

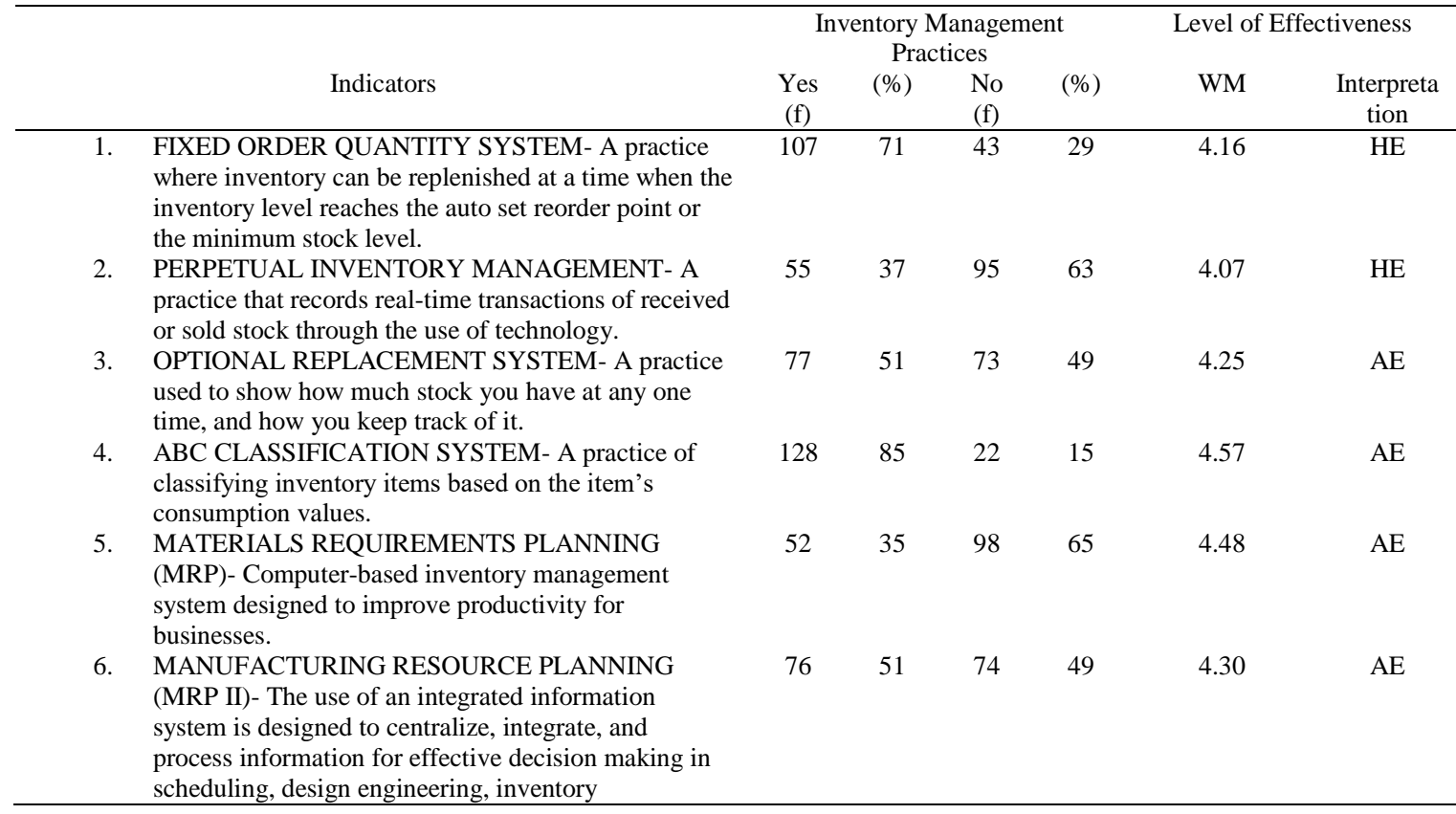




\section{International Journal of Current Science Research and Review}

ISSN: 2581-8341

Volume 04 Issue 11 November 2021

DOI: 10.47191/ijcsrr/V4-i11-06, Impact Factor: 5.825

IJCSRR@ 2021

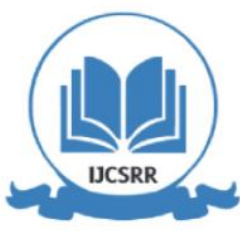

www.ijcsrr.org

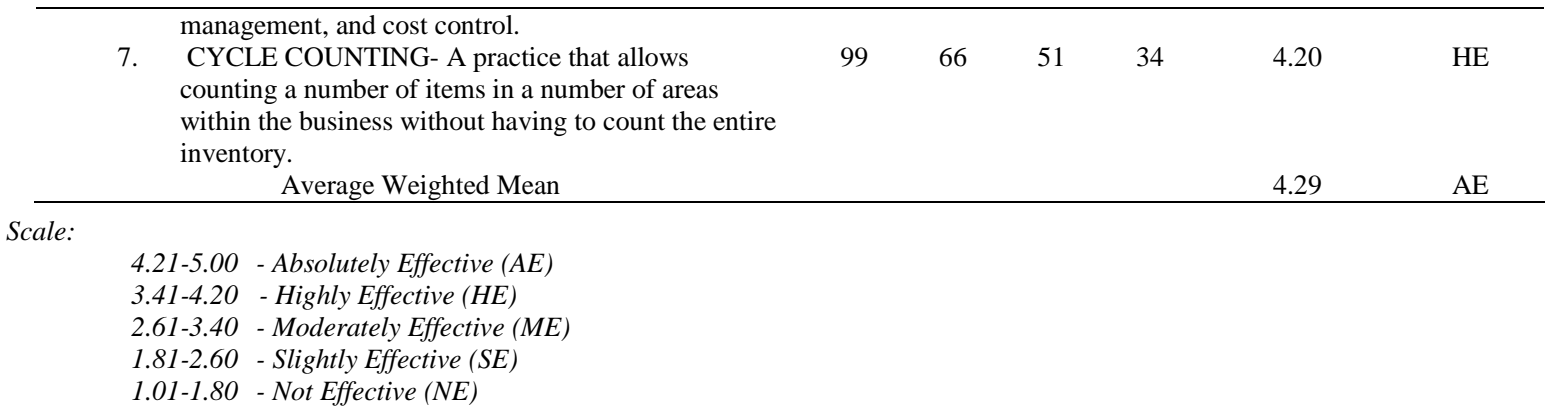

The presented data imply that the MSM grocery stores are efficient in implementing a storing that enables them to survive numerous challenges in their business operation. Data also imply that inventory management practices along storing of MSM grocery stores were averaging in the absolutely effective rating allowing them to identify and impose sound interventions to avoid more serious problems. This implies that the MSM grocery stores overcome challenges particularly for storing aspect or proper holding of their goods as part of their strength. However, in the study of Tayie (2012), it indicates that due to the methods used in storing, it requires more personnel to count the number in stock when necessary.

Along all the indicators for storing, ABC Classification had the highest rank, interpreted as absolutely effective. One reason that could explain the findings, most of the MSM grocery stores in municipality of Daet have their own perishable goods wherein it needs to be classified and monitored well since they are not only engaging in selling non-perishable products, they need to prioritize the most valuable products in their store through the use of ABC classification system. However, in a study of Ravinder and Mishra (2014), by reviewing eight (8) textbooks regarding operations and inventory management, he found out that in the current globalized hyper-responsive business environment, it is no longer an adequate guide to the management of inventories and multiple criteria have to be considered. He also added that ABC Classification is a mature concept that need to be revised, and in such revision will make the textbooks more relevant to the current business environment.

Meanwhile, the perpetual inventory management technique got the lowest result along all the indicators. This implies that majority of the MSM grocery stores in municipality of Daet, Camarines Norte relies on traditional practices like manual physical counting rather than recording in a real-time transaction of received or sold stock through the use of technology. This also implies that the MSM grocery stores are predominantly micro in sizes, meaning their resource capacity is minimal, not enough to have their own computerized technology.

This findings is supported by the study of Ngubane et al. (2015), revealed that the MSME respondents do not make adequate use of formal inventory management systems available to them like perpetual inventory management systems, rather, respondents prefer to use of more informal inventory management systems or the traditional manual practices (Periodic Inventory System).

Selling. The table shows that the FEFO and FIFO strategies appear the most practiced Inventory Management Practices among MSM grocery stores in Daet, Camarines Norte. 120 or 80 percent of MSM grocery stores are applying the First Expiry, First out (FEFO) while one 180 or 72 percent practiced First Out (FIFO).

In the selling variable, the indicator First Expiry, First Out (FEFO) was the most practiced inventory management practices among the majority of respondents with 102 or 80 percent. The results have shown that among the majority of the MSM grocery stores in Daet, Camarines Norte, products with the earliest expiration date are products that will be used or sold first.

However, even though the First Expiry, First out (FEFO) are the most practiced inventory management practice, based on the findings, the most effective among all the indicators for selling variable is Enterprise Resource Planning (ERP) with a weighted mean of 4.38 , or interpreted as absolutely effective.

Table 6. Inventory Management Practices of Grocery Stores and Assessment to its Level of Effectiveness in terms of Selling

\begin{tabular}{|c|c|c|c|c|c|c|c|}
\hline \multirow{2}{*}{\multicolumn{2}{|c|}{ Indicators }} & \multicolumn{4}{|c|}{ Inventory Management Practices } & \multicolumn{2}{|c|}{ Level of Effectiveness } \\
\hline & & $\begin{array}{l}\text { Yes } \\
\text { (f) }\end{array}$ & $(\%)$ & $\begin{array}{l}\text { No } \\
(f)\end{array}$ & $(\%)$ & WM & $\begin{array}{l}\text { Interpretat } \\
\text { ion }\end{array}$ \\
\hline 1. & $\begin{array}{l}\text { ENTERPRISE RESOURCE PLANNING- A } \\
\text { practice that uses software that contains applications } \\
\text { which automates business functions like production, } \\
\text { sales quoting, accounting, and more }\end{array}$ & 92 & 61 & 58 & 39 & 4.38 & $\overline{\mathrm{AE}}$ \\
\hline 2. & $\begin{array}{l}\text { FIRST IN, FIRST OUT (FIFO) - A practice that } \\
\text { assumes that the oldest products in a company's } \\
\text { inventory have been sold first }\end{array}$ & 108 & 72 & 42 & 28 & 4.22 & $\mathrm{AE}$ \\
\hline & $\begin{array}{l}\text { FIRST EXPIRY, FIRST OUT (FEFO)- Products } \\
\text { closest to expiration in the inventory have been sold }\end{array}$ & 120 & 80 & 30 & 20 & 4.18 & $\mathrm{HE}$ \\
\hline
\end{tabular}




\section{International Journal of Current Science Research and Review}

ISSN: 2581-8341

Volume 04 Issue 11 November 2021

DOI: 10.47191/ijcsrr/V4-i11-06, Impact Factor: 5.825

IJCSRR@ 2021

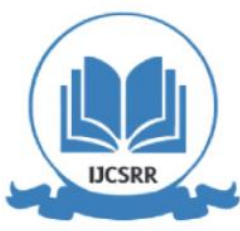

www.ijcsrr.org

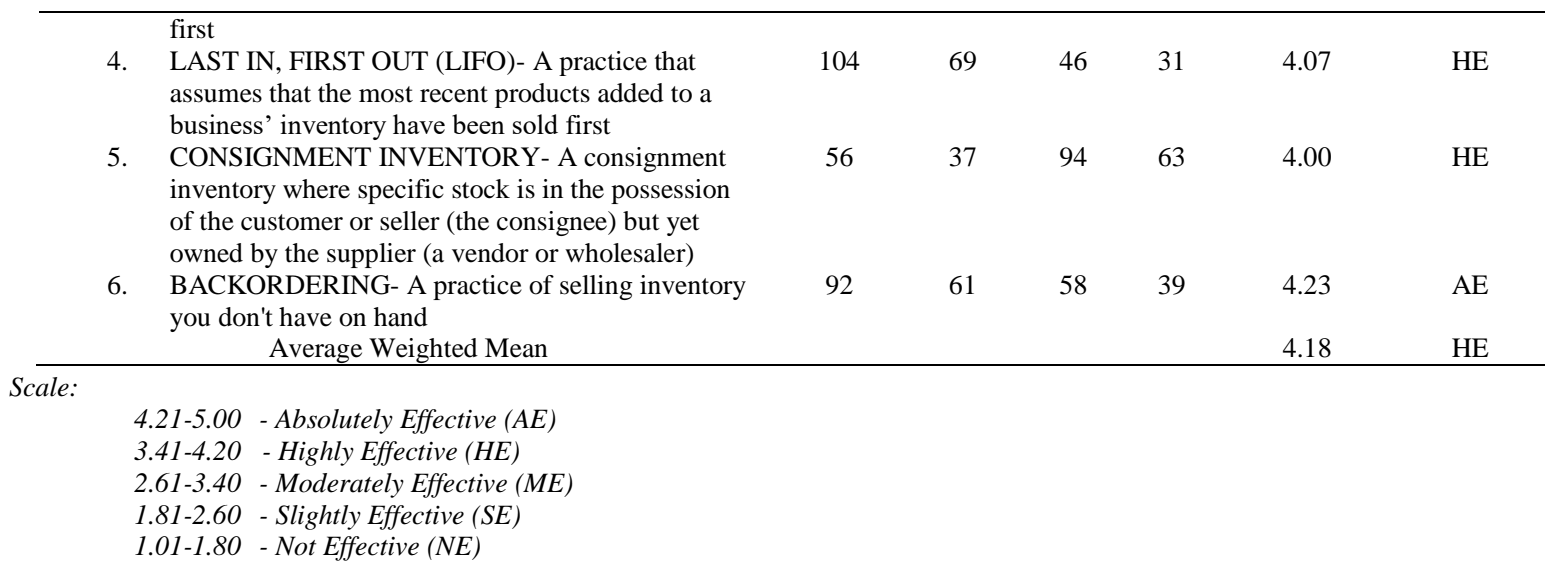

This implies that MSM grocery store know what products are needed to be sold first depending on their shelf life wherein losses and wastage through expiry of products is prevented. Also, the First expiry, first out (FEFO) method will help businesses to boost the confidence of the customers to buy their products. One major reason why the MSM grocery stores in Daet used FEFO method, most of them has different variety of products that have expiration dates such as canned goods, bottled drinks, meats, bakery goods and more. In this method, they allow them to get items out on shelves with the longest lead time on expiration dates and help in still a greater sense of confidence to their customers. It implies that the FEFO method is a preferred inventory control method as it allows products that are near to be expired to be sold first before those with longer expiry dates.

However, even though First expiry, first out (FEFO) is the most practiced inventory management, Enterprise Resource Planning (ERP) had the highest weighted mean which mean it is the most effective technique in all indicators in selling. One plausible reason why it is the most effective for MSM grocery stores in municipality of Daet because the ERP systems generally functions with the use of integrated software packages comprising of set of functional modules and integrate. Likewise, Amani and Fadlalla (2016) stated that the ERP systems are the most comprehensive business information systems that have come to surface, and provide solid informational foundation for operational processing as well as decision making with the condition to implement successfully.

Apart from all the indicators, the consignment is the less practiced and less effective one. According to Ciemcioch (2017), consignment inventory can add a layer of complexity to businesses, and as a consigner, the company shoulders much of the risks without a comparable rise in revenues. Thus, the consignment arrangement should be transparent to the end customer where the buyer often doesn't consider who gets paid or when.

One reason why it was the lowest indicator because most of the suppliers are not agreed with consignment method with grocery stores, due to the fact that grocery stores have a lot of varieties of products, suppliers will not allow larger number of items while the payment is late. It was supported by the study of Vrbova (2019) who found out that the most significant disadvantage of consignment inventory system for vendor or supplier's perspective is the long wait before payment, which is related to the findings of the current study.

\section{Test for Significant Relationship among Profile of MSM Grocery Stores to the Effectiveness of IM Practices}

Table 7 shows the significant relationship between the level of effectiveness of Inventory Management Practices and their profile where five (5) points of correlation can be pulled out based from correlation analysis made from the given figures. The correlation analysis was performed on respondents' profile and inventory management was reflected on the table below.

It can be observed from Table 7 that in terms of length of business operation's the level of effectiveness along sourcing and storing are not significant since the $\rho$-values such as .691 for sourcing and .421 for storing are greater than 0.05 significant level $(\rho>.05)$. However, it can be observed that selling, (with $\rho=.018$ ) is significantly correlated to the length of business operation, since $\rho<0.05$ significant level. Likewise, in terms of current capitalization, it can be observed that all indicators have no significant relationship on the aforementioned profile of the respondents. The obtained $\rho$-values such as $0.932,0.795$ and 0.939 are all greater than 0.05 significant level $(\rho>0.05)$. Finally, the profile of the respondents in terms of number of inventory management personnel garnered significant results along sourcing and storing with values of -0.166 (at 0.05 significant level) and -0.293 (at 0.01 significant level) respectively. It is along selling where the same profile has no significant relationship since it obtained a value of 0.021 . 


\section{International Journal of Current Science Research and Review}

ISSN: 2581-8341

Volume 04 Issue 11 November 2021

DOI: 10.47191/ijcsrr/V4-i11-06, Impact Factor: 5.825

IJCSRR@ 2021

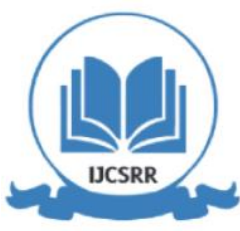

www.ijcsrr.org

Generally, the profile of the MSM grocery stores has no significant relationship to the assessment on their level of effectiveness of inventory management practices. Hence, with these results, the null hypothesis is accepted.

Table 7. Test for Significant Relationship between the Profile of MSM Grocery stores and the Assessment of the Level of Effectiveness of Inventory Management Practices

\begin{tabular}{lcccc}
\hline Indicators & $\begin{array}{c}\text { Length of the } \\
\text { Business } \\
\text { Operation }\end{array}$ & $\begin{array}{c}\text { Profile } \\
\text { Capitalization }\end{array}$ & $\begin{array}{c}\text { Number of Inventory } \\
\text { Management } \\
\text { Personnel }\end{array}$ & Interpretation \\
\hline Sourcing & $\begin{array}{c}.025 \\
(\rho=.691)\end{array}$ & $\begin{array}{c}-.007 \\
(\rho=.932\end{array}$ & $-.166^{*}$ & Not significant \\
Storing & -.052 & -.021 & $-.293^{* *}$ & Not Significant \\
Selling & $(\rho=.421)$ & $(\rho=.795)$ & .021 & Significant \\
& -.144 & .006 & & Not Significant \\
\hline
\end{tabular}

**Correlation is significant at 0.01 levels $(2$-tailed)

In the first test of significance, the length of business operation's level of effectiveness along sourcing and storing are not significant. These imply that the inventory practices along the two (2) indicators are not directly affecting the longevity of MSM grocery stores. One plausible explanation for this result might be that MSM grocery stores try to achieve better performance in difference kinds of means which have a straight connection to longevity and survival of the businesses. It is not clear whether the business' current performance result from sourcing and storing or other functions. Another possible explanation may be many MSM grocery stores do not emphasize, develop or cultivate sourcing and storing capability to a great extent that can lead to better business performance. It was sustained by the study of $\mathrm{Su}$ and Gargeya (2012), revealed that sourcing capability and firm performance was not statistically significant, which lead to business' longevity and existence.

This is quite contrary to the study of Wauna and Obwogi (2015) concluded that effective and efficient storing procedures have positive effect on inventory management and would have a positive effect on organizational performance, which is interrelated and vital to the company's length of business operation.

On the other hand, selling is significantly correlated to the length of business operations of MSM grocery stores. This implies that MSM grocery stores in municipality of Daet have connection with the selling practices which means that their existence has a great impact on the longevity of their business operations. One reason could be the majority of the grocery stores established for more than 20 years in Daet have their own exceptional style of practices when regards to selling of inventory and this is the reason why they are still existing and one of the top local grocery stores in Daet. One example that will support to this result is according to Javed (2012), claimed that FIFO method, one of the selling approaches for inventory management can saves money and time in calculating the exact cost of the inventory being sold because the cost will depend upon the most former cash flows of purchases to be used first. This implies that the methods on how these businesses use their selling practices are the reason why they are continuously developing which is connected to the lengthy existence of the MSM grocery stores.

Moreover, results show that current capitalization has no significant relationship to all indicators of inventory management such as sourcing, storing and selling. This implies that the MSM grocery stores' earnings and sustaining their needs are not connected and if they implement an effective any of sourcing, storing and selling approaches appropriately, it does not guarantee to have direct outcome in regards to preservation of assets and generating income. Other implication, it cannot conclude that if the MSM grocery stores have applied the best suitable approach using the three indicators, the businesses can earn more profits and capital.

However, Tabot (2015) have found out that poor working capital management practices have contributed heavily to the closing down of SMEs. Moreover, Muchaendepi et al., (2019), found out that majority of the respondents agreed that inventory management strategies used had a positive impact on the financial performance of SMEs, that means that there was a strong correlation between the inventory management strategies and working capital of SMEs. They also pointed out that inventory management strategies can affect both the working capital and profitability levels of an organization.

Furthermore, results show that the profile of the respondents in terms of number of inventory management personnel garnered significant results along sourcing and storing. This implies that if the business has greater number of inventory management staffs for sourcing and storing functions, there will be a vital influence on the efficiency and effectiveness of the business operations. Chitale and Gupta (2014) stated that managing inventory through employment of staff and everything 


\section{International Journal of Current Science Research and Review}

ISSN: 2581-8341

Volume 04 Issue 11 November 2021

DOI: 10.47191/ijcsrr/V4-i11-06, Impact Factor: 5.825

IJCSRR@ 2021

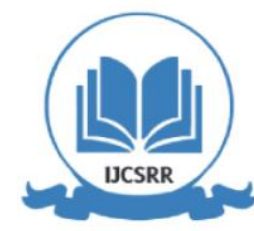

www.ijcsrr.org

concerned to human resources management reduces the costs incurred by the organization in the production departments and improved performance of the organization.

Yet, findings indicate the contrary, that selling has no significant relationship to the profile of the respondents in terms of number of inventory management personnel because it was shown that MSM grocery stores in Daet, Camarines Norte does not consider recruiting staffs for managing their inventory system in terms of selling. This implication was supported by the findings of the study of Nyamasege et al. (2013), who found out that the private organizations were deficient of competent staff to manage their stock and training requirements are not taken into account to fit the staff to the organization's routine requirements. In view of the findings, they suggested the need for organizations to recruit informed, competent and professionally qualified people to manage their stocks, among others.

\section{CONCLUSIONS}

From the results of the study, the researchers concluded that majority of the Micro, Small and Medium Grocery Stores in Daet, Camarines Norte have sustained, surpassed and withstand the first three years of criticalness and became fully-operational enterprises beyond four years after their time of establishment. Also, most of them did not assign in specific personnel who acts as the inventory management personnel and would man the inventory needs of the organization. These grocery stores have low current capitalization which is enough for them to survive and thrive in business. The grocery stores' inventory management practices along sourcing, storing and selling are assessed as absolutely effective that is why for them, they survive despite the odds of a slow growth rate. However, the business profile of the identified MSM grocery stores has no significant relationship to the assessed level of effectiveness of the inventory management practices; hence the null hypothesis is accepted.

font.

\section{ACKNOWLEDGMENTS}

The researchers' gratitude and heartfelt appreciation are extended to significant people who have made this research an edifying and worthwhile experience: to the respondents who have generously spared the researchers their time; the members of the panel of evaluators, the CNSC Graduate School Administrative staff headed by the Dean of the Graduate School; friends, families and loved ones who have always been the source of motivation and inspiration. To God be the Glory.

\section{LITERATURE CITED}

1. Intuit, QuickBooks. (2020). What is inventory management? https://www.tradegecko.com/inventory-management.

2. Sabure, M. (2020). The Influence of Inventory Control Management on Financial Organization Performance.

3. Kakwezi P. and Nyeko, S. (2014). Procurement Processes and Performance: Efficiency and Effectiveness of the Procurement function. https://www.researchgate.net/publication/228504902_procurement_processes_and_performance_efficiency_and_effectiven ess_of_the_procurement_function

4. Neely, A. (2015). The Performance Measurement Revolution: Why now and What Next. International Journal of operation and production management, 19(2), 205-228.

5. Aranda, V.M., and Ahmed, Y.A. (2016). Inventory Control and Organization of Warehouse. Bachelor Degree Project. University of Skovde. http://www.diva-portal.org/smash/get/diva2:954155/FULLTEXT01.pdf.

6. Vitasek, K. (2018). Storage and Inventory Control Best Practices. WA-based Supply Chain Visions.

7. Murray, J. (2020). What is inventory? The Balance Small Business. https://www.thebalancesmb.com/sorting-out-inventory-why-its-important-for-your-business-4041326.

8. Shin, S., Ennis, K.L., and Spurlin W.P. (2015). Effect of Inventory Management Efficiency on Profitability: Current Evidence from the U.S. Manufacturing Industry, Journal of Economics and Economic Education Research, Vol. 16 (1), 98.

9. Salawati, S., Tinggi, M., \& Kadri, N. (2012). Inventory Management in Malasyian Construcion Firms: Impact on Performance. SIU Journal management, 2, 59-60. 74.D

10. Njoroge, J.K., Ongeti, W.J., Kinuu, D. and Kasomi, F.M. (2016). Does external environment influence organizational performance? The case of Kenyan State Corporations. Management and Organizational Studies, 3(3), 41-51. 


\section{International Journal of Current Science Research and Review}

ISSN: 2581-8341

Volume 04 Issue 11 November 2021

DOI: 10.47191/ijcsrr/V4-i10-14, Impact Factor: 5.825

IJCSRR@ 2021

www.ijcsrr.org

11. Kuznetsova, N.V., and Alekseeva, E.A. (2016). The role of the external environment in increasing the competitiveness of the organization. In the collection: Achievements of modern science: a materials collection of the XIII International Scientific and Practical Conference, 417-423

12. Ferreiro F.J., Rodríguez-Rodriguez, G., and Vaquero, A. (2018). Public Investment in Business incubators, is it better than doing nothing? Int. J. Entrep. Small Business. 33, 553-574

13. Hamzani, U. and Achmad, D. (2015). The Performance of Micro, Small, and Medium Enterprises (MSMEs): Indigenous Ethnic Versus Non-Indigenous Ethnic.

14. Chitale A.K and Gupta R.C (2014), materials management supply chain perspective (6th edition) PHI learning private limited, New Delhi.

15. Arunkumar and Nishad I. (2018). Analysis of Inventory Management by Using Economic Order Quantity Model - A Case Study. International Journal for Research in Applied Science \& Engineering Technology (IJRASET). Volume 6 Issue VI.

16. Victor, V.K. (2018). Inventory Management Practices and Operational Performance of Small and Medium Enterprises in Kenya: A Study of Pharmaceutical manufacturers in Nairobi, Kenya. Degree of Master of Business Administration, School of Business, University of Nairobi.

17. Tayie, N.E. (2012). Improving warehouse and inventory management: Operational Efficiency and Transport Safety. Degree Programme in Logistics Engineering. JAMK University of Applied Sciences, Finland.

18. Ravinder, H., and Misra, R. (2014). ABC Analysis for Inventory Management: Bridging the Gap between Research and Classroom. American Journal of Business Education - Third Quarter. Volume 7, No 3.

19. Ngubane, N., Mayekiso, S., Sikota, S., Fitshane, S., Matsoso, M. and Juan-Pierré, B. (2015). Inventory Management Systems used by Manufacturing Small Medium and Micro Enterprises in Cape Town. Mediterranean Journal of Social Sciences, 6(1), p.382.

20. Amani, F., and Fadlalla A. (2016). Organizing ERP research: a knowledge-centric approach. Journal of Enterprise Information Management. DOI:10.1108/JEIM-09-2015-0085.

21. Ciemcioch, S. (2019). Is Consignment Inventory the Right Choice for Your Business? https://www.warehouseanywhere.com/resources/consignment-inventory/

22. Vrbova, I.P. (2019). Risks elimination while consignment stock concept implementation. Dissertation Thesis. University of Pardubice. Department of Business Economics and Management.

23. Su, J., and Gargeya, V. (2012), "Strategic sourcing, sourcing capability and firm performance in the US textile and apparel industry", Strategic Outsourcing: An International Journal, Vol. 5 Iss: 2 pp. 145 - 165

24. Wauna S., and Obwogi, J. (2015). An Assessment of the Effects of Inventory Management Procedures on Performance of Kengen. International Journal of Scientific and Research Publications, Vol. 5, Issue 10. ISSN 2250-3153.

25. Javed R. (2012). Advantages and disadvantages of first-in, first-out (FIFO) method. https://www.accountingformanagement.org/advantages-and-disadvantages-of-fifo/

26. Tabot, E. S. (2015) The working-capital management practices of small medium and micro enterprises in the cape metropole, thesis submitted at Cape Peninsula University of Technology.

27. Muchaendepi, W., Mbohwa, Cb., Hamandishe, T.C., and Kanyepe, J.D. (2019). Inventory Management and Performance of SMEs in the Manufacturing Sector of Harare. 16th Global Conference on Sustainable Manufacturing (GCSM).

28. Chitale A.K and Gupta R.C (2014), Materials Management Supply Chain Perspective (6th Edition) PHI Learning Private Limited, New Delhi.

29. Nyamasege, D., Sixtus, O., Kerere, L. and Obenge, P. (2013). Cost minimization through effective stock management in private organizations, Challenges and recommendations. International Journal of Development and Sustainability, 3(4): 902-08. 